\title{
In situ observations of meteor smoke particles (MSP) during the Geminids 2010: constraints on MSP size, work function and composition
}

\author{
M. Rapp ${ }^{1, * * * *}$, J. M. C. Plane ${ }^{2}$, B. Strelnikov ${ }^{1}$, G. Stober ${ }^{1}$, S. Ernst ${ }^{1}$, J. Hedin ${ }^{3}$, M. Friedrich ${ }^{4}$, and U.-P. Hoppe ${ }^{5, * * *}$ \\ ${ }^{1}$ Leibniz-Institute of Atmospheric Physics, Kühlungsborn, Germany \\ ${ }^{2}$ School of Chemistry, University of Leeds, UK \\ ${ }^{3}$ Department of Meteorology, Stockholm University, Stockholm, Sweden \\ ${ }^{4}$ Institute of Communication Networks and Satellite Communications, Graz University of Technology, Austria \\ ${ }^{5}$ University of Oslo, Department of Physics, Oslo, Norway \\ *now at: Deutsches Zentrum für Luft- und Raumfahrt, Institut für Physik der Atmosphäre, Oberpfaffenhofen, Germany \\ ** now at: Meteorologisches Institut München, Ludwig-Maximilian-Universität München, Munich, Germany \\ **** on leave from: Norwegian Defence Research Establishment (FFI), Kjeller, Norway \\ Correspondence to: M. Rapp (markus.rapp@dlr.de)
}

Received: 2 September 2012 - Revised: 9 November 2012 - Accepted: 12 November 2012 - Published: 12 December 2012

\begin{abstract}
We present in situ observations of meteoric smoke particles (MSP) obtained during three sounding rocket flights in December 2010 in the frame of the final campaign of the Norwegian-German ECOMA project $($ ECOMA $=$ Existence and Charge state Of meteoric smoke particles in the Middle Atmosphere). The flights were conducted before, at the maximum activity, and after the decline of the Geminids which is one of the major meteor showers over the year. Measurements with the ECOMA particle detector yield both profiles of naturally charged particles (Faraday cup measurement) as well as profiles of photoelectrons emitted by the MSPs due to their irradiation by photons of a xenon-flash lamp. The column density of negatively charged MSPs decreased steadily from flight to flight which is in agreement with a corresponding decrease of the sporadic meteor flux recorded during the same period. This implies that the sporadic meteors are a major source of MSPs while the additional influx due to the shower meteors apparently did not play any significant role. Surprisingly, the profiles of photoelectrons are only partly compatible with this observation: while the photoelectron current profiles obtained during the first and third flight of the campaign showed a qualitatively similar behaviour as the MSP charge density data, the profile from the second flight (i.e., at the peak of the Geminids) shows much smaller photoelectron currents. This may tentatively be
\end{abstract}

interpreted as a different MSP composition (and, hence, different photoelectric properties) during this second flight, but at this stage we are not in a position to conclude that there is a cause and effect relation between the Geminids and this observation. Finally, the ECOMA particle detector used during the first and third flight employed three instead of only one xenon flash lamp where each of the three lamps used for one flight had a different window material resulting in different cut off wavelengths for these three lamp types. Taking into account these data along with simple model estimates as well as rigorous quantum chemical calculations, it is argued that constraints on MSP sizes, work function and composition can be inferred. Comparing the measured data to a simple model of the photoelectron currents, we tentatively conclude that we observed MSPs in the $0.5-3 \mathrm{~nm}$ size range with generally increasing particle size with decreasing altitude. Notably, this size information can be obtained because different MSP particle sizes are expected to result in different work functions which is both supported by simple classical arguments as well as quantum chemical calculations. Based on this, the MSP work function can be estimated to lie in the range from $\sim 4-4.6 \mathrm{eV}$. Finally, electronic structure calculations indicate that the low work function of the MSP measured by ECOMA indicates that $\mathrm{Fe}$ and $\mathrm{Mg}$ hydroxide 


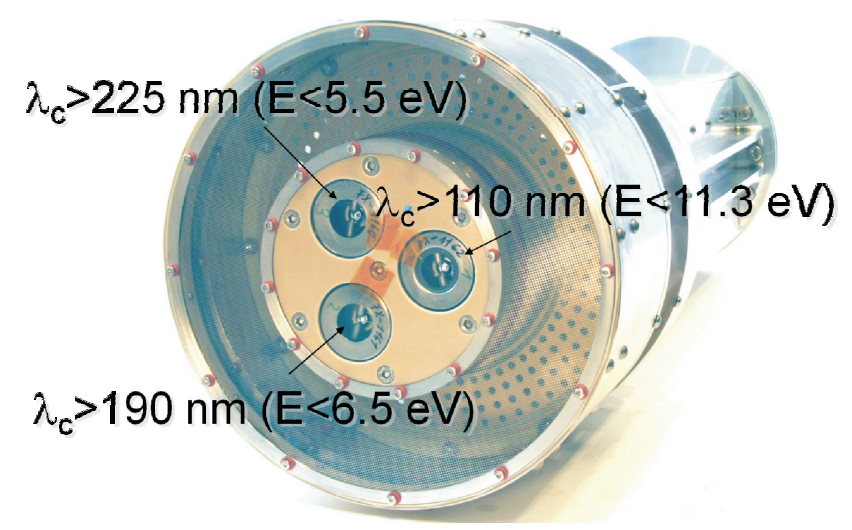

Fig. 1. Photograph of the modified ECOMA particle detector with three flashlamps employing three different window materials and, hence, different wavelength cutoffs. The used flashlamps are supplied by Perkin Elmer, product numbers FX1162 (cutoff wavelength at $110 \mathrm{~nm}$ ), FX1161 (cutoff at $190 \mathrm{~nm}$ ), and FX1160 (cutoff at $225 \mathrm{~nm}$ ).

clusters, rather than metal silicates, are the major constituents of the smoke particles.

Keywords. Atmospheric composition and structure (Aerosols and particles; Middle atmosphere - composition and chemistry) - Ionosphere (Ion chemistry and composition)

\section{Introduction}

In recent years, meteoric smoke particles (MSP) have attracted great interest in the middle atmosphere science community since these particles are believed to be involved in a large number of important geophysical phenomena. Among these are the nucleation of mesospheric ice particles (e.g., Rapp and Thomas, 2006), the mesospheric metal chemistry (Plane, 2003), the D-region charge balance (e.g., Rapp and Lübken, 2001), the heterogeneous formation of water vapour in the mesosphere (Summers et al., 2001), and even the nucleation of polar stratospheric cloud particles which play a major role in the formation of the ozone hole (e.g., Voigt et al., 2005). While some progress regarding the experimental investigation of these atmospheric trace species has been made over the past years with sounding rockets (e.g., Schulte and Arnold, 1992; Gelinas et al., 1998; Horányi et al., 2000; Rapp et al., 2005; Lynch et al., 2005; Barjatya and Swenson, 2006; Amyx et al., 2008; Strelnikova et al., 2009; Rapp et al., 2010), incoherent scatter radars (Rapp et al., 2007; Strelnikova et al., 2007; Fentzke et al., 2009), satellites (Hervig et al., 2009, 2012), and laboratory studies (Saunders and Plane, 2006), much of our knowledge about these particles still relies on model results (e.g., Hunten et al., 1980; Gabrielli et al., 2004; Megner et al., 2006, 2008; Bardeen et al., 2008). Among other things, very little is still known about the physical and chemical properties of MSPs such as their composition and their electrical and optical properties.

In order to contribute to filling this gap, a major international sounding rocket campaign was conducted in December 2010 from the North-Norwegian Andøya Rocket Range $\left(69^{\circ} \mathrm{N}, 16^{\circ} \mathrm{E}\right)$. This sounding rocket campaign was the final in a series of campaigns in the frame of the Norwegian/German ECOMA-project (ECOMA = Existence and Charge state Of meteoric smoke particles in the Middle Atmosphere; see Rapp et al., 2011, for a detailed project description and an overview of results from previous campaigns). The primary aim of this final campaign was to investigate the effect of a major meteor shower (i.e., the Geminids) on the properties of the MSPs. In addition, an advanced version of the ECOMA particle detector (see below) was employed in order to constrain important MSP properties such as their work function. As the backbone of this campaign a total of three sounding rockets were launched all carrying largely identical instrumented payloads.

The current study primarily focuses on the results obtained with the ECOMA particle detector during the final campaign in December 2010. For this purpose, this article is organised as follows: In Sect. 2 we shortly review the experimental techniques employed in this study after which we present our observations in Sect. 3. These are subsequently discussed in Sect. 4, thereafter we conclude in Sect. 5 in which also an outlook for future work is given.

\section{The ECOMA-particle detector: principle of operation and improvements}

The ECOMA particle detector (PD) has been described in detail in Rapp and Strelnikova (2009) and Rapp et al. (2010). In short, the PD is a combination of a classical Faraday cup for the detection of charged heavy aerosol particles as first described by Havnes et al. (1996) and a xenon flashlamp for the active photoionization of MSP and ice particles and the subsequent detection of photoelectrons. During the campaign in December 2010 all three payloads carried one of these detectors. In addition, in two out of these three sounding rocket flights an improved version of the detector has been launched which will now be described in more detail.

Figure 1 shows a photograph of this improved PD. The main difference to its predecessor version is the addition of two more flashlamps which are clearly visible in the centre of the PD. All of these flashlights are basically identical Perkin Elmer FX1160-series lamps. The only difference between these three flashlamps is that they are equipped with three different windows so that the emitted spectra have different lower cut off wavelengths. These range from $\sim 110 \mathrm{~nm}$ for lamp type FX1162 (which is the one originally used and which has consistently been used for all ECOMA-flights), over $190 \mathrm{~nm}$ for type FX1161, to $225 \mathrm{~nm}$ for type FX1160. 


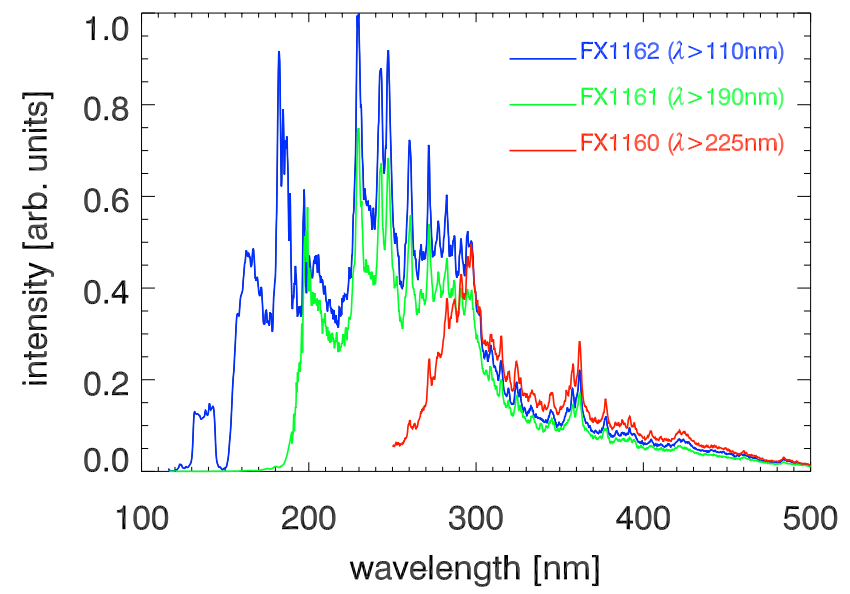

Fig. 2. Spectra of the different flash lamp types used in the improved version of the ECOMA particle detector. These spectra have been obtained with a vacuum ultraviolet grating spectrometer (see Ernst, 2012, for more details).

The spectral characteristics of these three different lamp types have been characterised with a vacuum ultraviolet grating spectrometer and the results are presented in Fig. 2 (see Ernst, 2012, for more details). This figure clearly demonstrates that the various lamps basically emit identical spectra which are, however, cut off at the different wavelengths owing to the optical properties of the different window materials.

The functional principle of the new detector version is as follows: as in the previous PD-versions a xenon flash and the subsequent detection of corresponding photoelectron pulses (sampled at a data rate of $100 \mathrm{kHz}$ and a resolution of $16 \mathrm{bit}$ ) occurs every $64 \mathrm{~ms}$, i.e., at a rate of $15.6 \mathrm{~Hz}$. However, for this improved version each flash lamp is only triggered every third time, i.e., the three flash lamps emit their flashes in a cyclic manner. This means that the actual repetition time for one given flash lamp is $192 \mathrm{~ms}$ as compared to $64 \mathrm{~ms}$ for the older version of the ECOMA PD.

A typical data sample resulting from this measurement sequence is presented in Fig. 3 which shows raw data from flight ECOMA07 (see below for more details). Each of the prominent photoelectron peaks can be uniquely related to the firing of one of the flashlamps by means of corresponding data flags transmitted with the housekeeping data of the experiment. As expected based on the different spectral characteristics of the three different flash lamps the photoelectron peaks have different amplitudes owing to the different total number of photons available for photoionization and their correspondingly different spectral distribution. It is this difference between the amplitudes of the various photoelectron peaks that principally contains information on the microphysical and photoelectrical properties of the ionized particles - this will be discussed in detail in Sect. 4 .

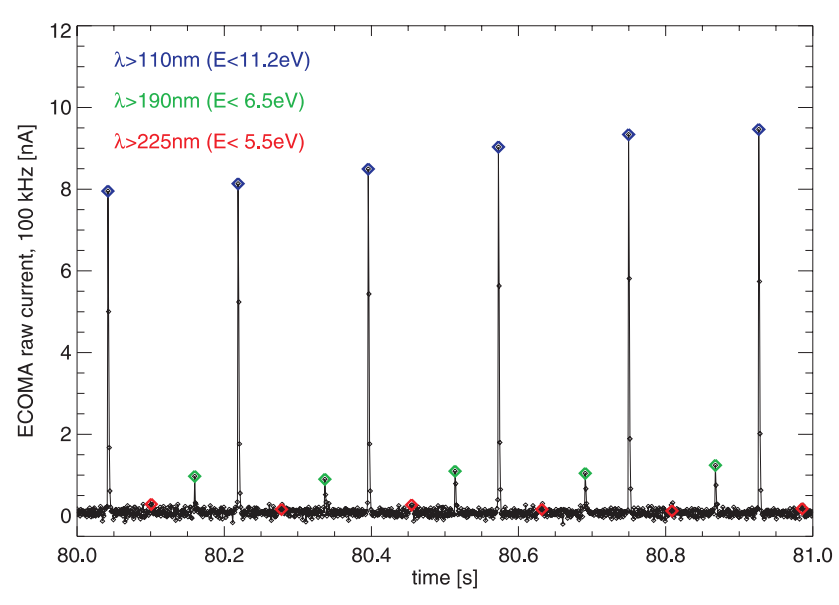

Fig. 3. Time series of currents recorded with the ECOMA particle detector at a rate of $100 \mathrm{kHz}$ and a resolution of 16 bit. Diamonds mark current peaks caused by photoelectrons reaching the electrode shortly after the firing of corresponding flash lamps. Different colours mark the different flash lamp types as indicated in the insert. In the following, the time series of photoelectron peaks are denoted as photoelectron currents for brevity.

Summarising, this new version of the ECOMA PD provides four different data products: the "classical" Faraday cup-current owing to naturally charged particles which can penetrate into the detector, and the three photoelectron currents (more precisely the time series of maximum photoelectron pulses) due to the three different flash lamps with different maximum photon energies. In contrast, the older version of the detector only delivers the Faraday Cup-current and one photoelectron current for flashlamp type FX1162, i.e., the one with maximum photon energy.

\section{Atmospheric observations}

\subsection{Morphology of MSP observations during the evolu- tion of the Geminids}

As mentioned in the introduction, the primary focus of the campaign in December 2010 was the investigation of the effect of the Geminids (as one of the major meteor showers) on the properties of the MSPs. Consequently, the three sounding rockets were distributed in time so that the first (labelled ECOMA07) was launched on 4 December well before the onset of the Geminids, the second one (ECOMA08) was launched close to the peak of the Geminids on 13 December, and the final one (ECOMA09) after the shower had already decayed, i.e., on 19 December. See Table 1 for a summary of flight dates, times and launch conditions. In order to illustrate the meteor activity during the campaign period, Fig. 4 shows half-hourly meteor count rates as observed with the IAP meteor radar located in the vicinity of the Andøya Rocket Range (see Stober et al., 2012, for a detailed analysis of these radar 
Table 1. Date, time and launch conditions during ECOMA-2010.

\begin{tabular}{lrrrr}
\hline Label & Date & Time [UT] & Apogee $[\mathrm{km}]$ & Launch conditions \\
\hline ECOMA07 & 4 Dec 2010 & $04: 21$ & 135.7 & before Geminids, extremely quiet D-region \\
ECOMA08 & 13 Dec 2010 & $03: 24$ & 138.3 & peak of Geminids, moderately dist. D-region \\
ECOMA09 & 19 Dec 2010 & $02: 36$ & 135.5 & after Geminids, moderately dist. D-region \\
\hline
\end{tabular}

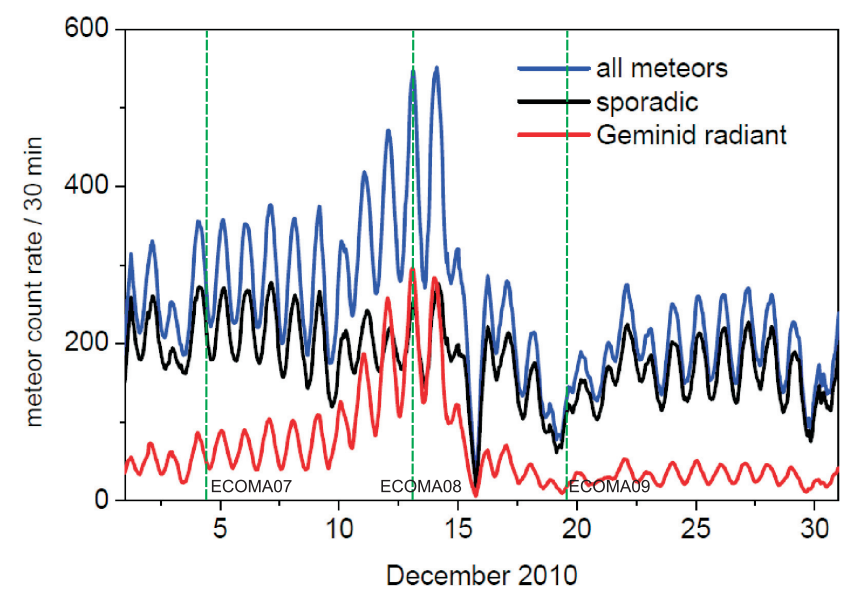

Fig. 4. Time variation of half-hourly meteor count rates as observed with the IAP meteor radar located in the vicinity of the Andøya Rocket Range in December 2010. The blue curve shows the total count rate, whereas the red curve is for Geminid meteors and the black curve for the background sporadics. Green dashed vertical lines indicate the launch times of the three ECOMA sounding rockets.

observations). This figure clearly shows the very different meteor count rates during the three rocket flights and underlines that the mission plan to launch one rocket before, one at the peak and one after the peak activity was indeed met.

We next turn to the corresponding MSP observations and present the Faraday cup data from all three flights in Fig. 5. Before going into detail, we note that the lower altitude cut off seen in the data at about $80 \mathrm{~km}$ is a well known feature of this type of measurement and is caused by aerodynamical effects. This means that owing to the density enhancement before the supersonically moving instruments (i.e., the "shock front") light particles are deflected away from the instrument and, hence, can not reach the PD electrode. This effect leads to an altitude dependent limit of detectable particle sizes which strongly increases with decreasing altitude (and increasing density) so that at altitudes below $\sim 80 \mathrm{~km}$ this type of instrument essentially has zero detection efficiency for small MSP (Horányi et al., 1999; Hedin et al., 2007; Strelnikova et al., 2009).

Considering further details presented in Fig. 5 we see that the measurements obtained on the upleg part of the rocket trajectory generally show negative values indicating the presence of negatively charged MSP at the lower altitudes. At larger altitudes, the profiles all turn to positive values and remain positive until apogee (at $\sim 130 \mathrm{~km}$; here only shown up to $105 \mathrm{~km}$ ). Since charged meteoric particles are not expected to exist at these large altitudes, we assume that these positive signatures are not evidence of positively charged particles, but likely contamination of the measurements with leakage currents due to positive ions. This hypothesis is indeed supported by considering the measurements obtained on the downleg part of the rocket trajectory when the PD is no longer facing the ram direction of the rocket. Since all ECOMA rockets were spin-stabilised, the ECOMA PD which is mounted on the top deck of the payload is in the wake of the rocket on the downleg. Hence, naturally charged particles can by no means enter the detector volume such that current signatures measured during this part of the flight are clear evidence for leakage currents from the ambient plasma. These downleg data are shown with light blue lines in all three panels in Fig. 5. Comparing upleg and downleg measurements reveals that the positive currents at the upper altitudes are indeed caused by these leakage currents since they both show very similar structures at altitudes above the MSP-layers. As a first approximation, the downleg data can be used to correct the upleg data and remove the leakage current contribution (of course assuming similar background plasma conditions on up- and downleg - which is generally supported by our onboard plasma measurements with various instruments). We note, however, that the plasma densities observed during ECOMA09 were about twice as large on downleg as on upleg so that the used method possibly leads to an overcorrection (Bekkeng et al., 2012). Nevertheless, this procedure works generally well for the three rocket flights which underlines that the positive currents seen at some altitudes on upleg must be considered as artifacts. Therefore, for the following discussion, we will only focus on the negative particle signatures which are summarised in Fig. 6.

Figure 6 reveals that the observed MSP "layers" indeed showed a large variation over the three sounding rocket flights. Surprisingly, however, there appears to be a steady decay of the total MSP amount as is most clearly seen when determining the column charge density of the observed particles, i.e., the vertical integral over the particle layers. This reveals that the column charge density decreased from $5.2 \times 10^{7} \mathrm{e} \mathrm{cm}^{-2}$ on 4 December, over $4.3 \times 10^{7} \mathrm{e} \mathrm{cm}^{-2}$ on 13 December, to $3.0 \times 10^{7} \mathrm{e} \mathrm{cm}^{-2}$ on 19 December. Also, it appears that the uppermost altitude of particle detection decreased from about 95 to $87 \mathrm{~km}$ and that the lowermost 

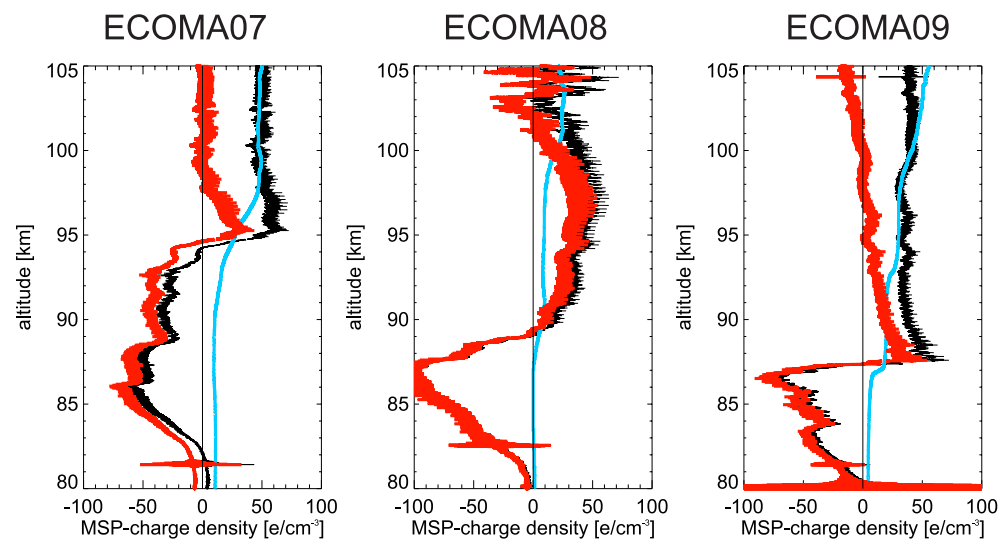

Fig. 5. Overview of all Faraday cup measurements of charged MSP obtained during ECOMA-2010. Black lines show upleg-data. Light blue lines show downleg data smoothed over 5000 data points. Taking the difference between both allows us to largely eliminate contamination due to positive ions (see text for details). The corrected profiles are shown in red.



Fig. 6. Overview of all measurements of negatively charged meteor smoke particles during ECOMA-2010. The legend identifies the three different rocket flights (see Table 1) and further states the negative charge column density $(\mathrm{Cd})$ observed in each flight.

altitude of particle detection decreased from about 82 to $80 \mathrm{~km}$ over the course of the three rocket launches. Since the same general features are also seen in the completely independent photoelectron data (see Fig. 7 and corresponding discussion below) we are confident that this observed change is caused by a change of the smoke distribution and not an artifact caused, for example, by varying ambient plasma conditions.

We note that this observed variation of the MSP column charge density is in stark contrast to an intuitive expectation according to which a larger meteor flux (i.e., during a major meteor shower) should result in a larger amount of MSPs. However, the total mass flux generated by a meteor shower depends on the particle size of the corresponding meteoroids. According to Ceplecha et al. (1998) the maximum mass flux into the upper atmosphere occurs at masses around $10^{-9} \mathrm{~kg}$

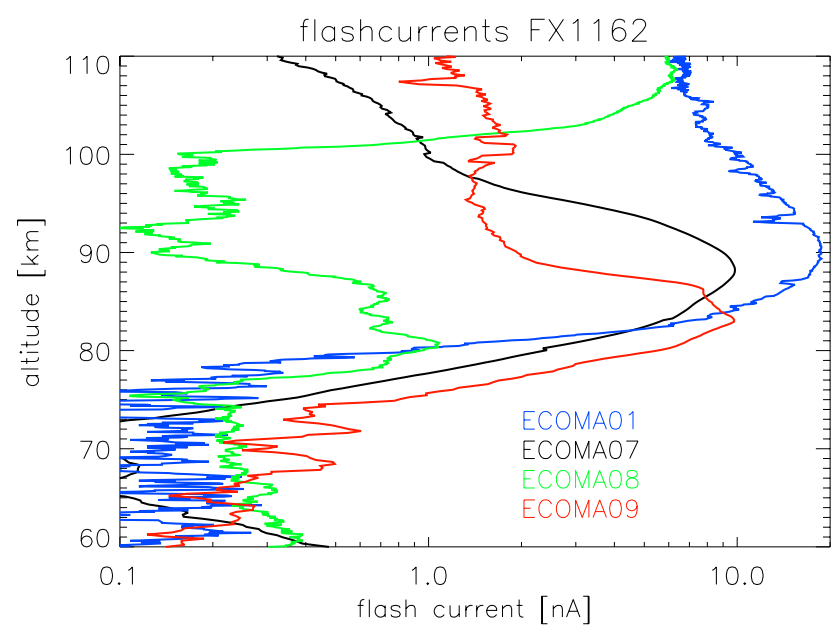

Fig. 7. Overview of photoelectron currents obtained during all ECOMA flights outside the polar summer, i.e., ECOMA01, ECOMA07, ECOMA08 and ECOMA09 obtained with the flashlamps with the largest photon energy, i.e., type FX1162 (i.e., $\lambda>$ $110 \mathrm{~nm})$.

and drops steeply to both smaller and larger particle masses. In the companion paper by Stober et al. (2012), however, it is shown that the Geminid meteor shower contains more larger than smaller particles with an observed peak of the mass distribution at about $10^{-7} \mathrm{~kg}$. Hence, the contribution of the Geminids to the total mass input into the middle atmosphere can be considered as almost negligible. This issue is further discussed in the companion paper by Dunker et al. (2012) who also consider the time evolution of the Na layer during this period as well as the evolution of the sporadic meteor flux. They show that both the flux of sporadic meteors, the sodium column density and the column density of MSPs steadily decreased over the time of the ECOMA campaign which possibly implies that a reduced flux of sporadic 
meteors is the cause for the decay of the two other quantities (while apparently the additional flux of the Geminids had no obvious measurable impact; see Dunker et al. (2012) for a detailed discussion). Here, we will next consider whether the ECOMA photoelectron measurements show a similarly coherent picture.

To start, we first compare the photoelectron currents from all three rocket flights for the flashlamp type which was operated on all payloads, i.e., the lamp type with the largest photon energy, type FX1162. The corresponding altitude profiles from all three flights are presented in Fig. 7. This figure shows an unexpected result: While the data from the flights ECOMA07 and ECOMA09 show a similar tendency with regard to the general extent of the layer as the Faraday cup data (broader MSP layer during ECOMA07 and and lower in altitude MSP detection during ECOMA09), the most striking fact is the much reduced photoelectron currents during ECOMA08, i.e., at the peak of the Geminids. This untypically low level of the photoelectron current is further underlined when additionally taking into account the results from ECOMA01 which was also launched outside the polar summer season and during which the same instrument type as during ECOMA08 was used. The photoelectron current of ECOMA01 is similar to the ones of ECOMA07 and ECOMA09, but the one from ECOMA08 is indeed significantly smaller.

Puzzled by this finding, we double checked whether the corresponding flashlamp was possibly erroneously mixed up with a different lamp type. As the outcome of this check, we are in a position to rule out this possibility. Also, all housekeeping information during this rocket flight support the nominal function of the instrument and its flashlamp. In addition, we note that other external factors such as payload charging do not show any striking differences between the three rocket flights (see Bekkeng et al., 2012, for details). Furthermore, we note that laboratory tests conducted before launch with all three lamps reveal that the lamp launched onboard ECOMA08 had similar characteristics as the one launched onboard ECOMA09 and that both were even $\sim 20 \%$ stronger (i.e., resulted in larger photoelectron currents when flashed at a lab target; see Fig. 6 in Rapp and Strelnikova (2009) for a description of the corresponding laboratory experiment) than the one launched onboard ECOMA07. Finally, we note that the ECOMA08-data itself confirms that the proper flash lamp was installed and that the instrument was functioning as it was supposed to: This can in fact be inferred from the large current increase seen above $100 \mathrm{~km}$ which must be due to he photoionization of NO (see the corresponding discussion in Rapp and Strelnikova, 2009). Note that the corresponding increase of NO as compared to ECOMA07 is caused by strong auroral particle precipitation as confirmed by the onboard photometer measurements (J. Hedin, private communication). Since only flash lamp type FX1162 emits sufficiently energetic photons to photoionize $\mathrm{NO}$, this is strong support that the lamp was functioning as it should. This is also further confirmed by the fact that corresponding maximum currents fall into the range of values seen during previous flights.

Taking all these arguments into account, we conclude that the reduced photoelectron current observed during ECOMA08 at altitudes below $100 \mathrm{~km}$ must be considered as a real geophysical result. What we may conclude from this is that our observations provide strong indications that the MSP observed during ECOMA08 were of different composition (i.e., had different photoelectric properties) than during ECOMA07 and ECOMA09 while other properties like number density and charge were similar. This is implied by their similar Faraday cup currents (which to first order are proportional to the MSP number density), but their very different photoelectron currents. Whether or not this different composition is related to the flux of Geminid meteors (which have been reported to have a composition different from sporadic meteors, see Borovicka, 2006) or just evidence of natural variability cannot be resolved based on our data, but will require new additional measurements in the future.

\subsection{Spectral characteristics of MSP photoelectron data}

Next, we turn to the information obtained from the improved versions of the ECOMA PD as launched onboard ECOMA07 and ECOMA09. The upper panels of Fig. 8 show the photoelectron currents due to the three different flash lamp types for both flights. Note that we have also indicated the $2 \sigma$ noise level of these data as the black dotted horizontal lines. Comparing the measured current profiles to this noise level clearly shows that in both flights, signatures of MSP have been recorded with all flash lamps. Furthermore, this comparison clearly shows that only the photoelectron currents due to flash lamp type FX1162 with largest photon energies (shown by the black diamonds) exceed the noise level above altitudes of about $95 \mathrm{~km}$ (ECOMA07) and $90 \mathrm{~km}$ (ECOMA09), respectively. Since only flash lamp type FX1162 emits photons which may ionize atmospheric NO, this result provides strong support to our earlier hypothesis that these large altitude photoelectron currents are not related to MSP, but rather to NO (Rapp and Strelnikova, 2009; Rapp et al., 2010). In fact, we may find even stronger support based on the data of ECOMA07 since photometer measurements on this payload provide an independent estimate of the NO number density (see Hedin et al., 2012, for details). While the analysis of Hedin et al. (2012) reveals that estimates of absolute NO number densities based on both techniques diverge by a factor of $\sim 4-5$, here we simply scale the photometerbased NO-profile to the photoelectron current above $100 \mathrm{~km}$ (orange curve in left upper panel in Fig. 8). This exercise shows that the two profiles fit perfectly at altitudes above $100 \mathrm{~km}$ and, hence, strongly support our hypothesis that these large altitude currents are indeed a measure of NO. Even more to that, this agreement suggests that the scaled photometer profile can be used to correct the photoelectron data 

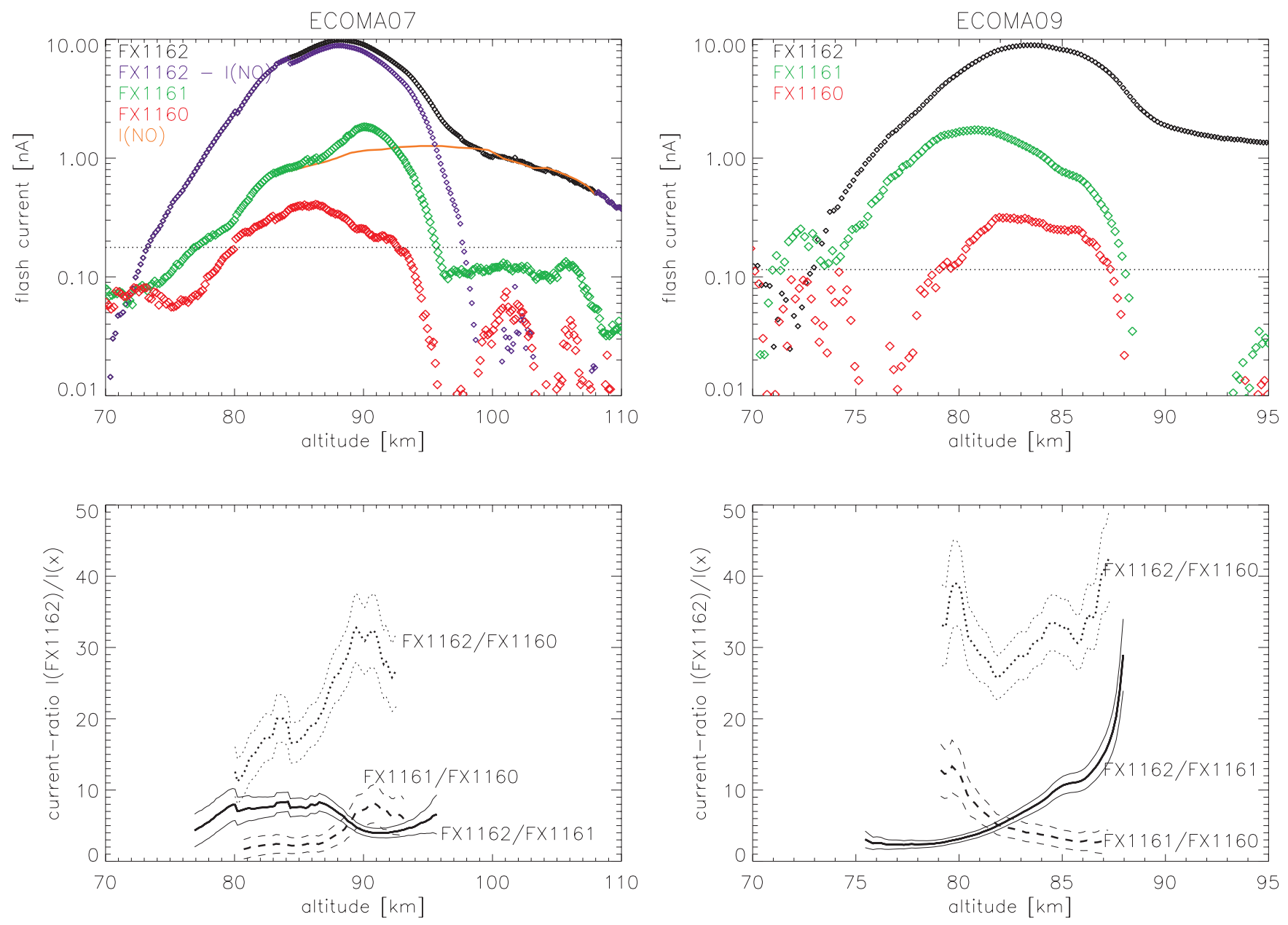

Fig. 8. Upper panels: Photoelectron currents measured during flights ECOMA07 (left) and ECOMA08 (right). Black, green and red symbols indicate currents owing to different flashlamps (see legend). The dotted horizontal line marks the $2 \sigma$-noise level of the unsmoothed measurements. In the upper left panel, the orange curve further shows the current-contribution from NO which was independently measured with photometers by the Stockholm group. Unfortunately, such data are not available for ECOMA09. The dark blue symbols mark the data of the FX1162 flashlamp corrected for the contribution owing to NO. Lower panels: Profiles of current ratios along with their $2 \sigma$-error bars, for altitude ranges in which both measurements exceeded the $2 \sigma$-noise level of the unsmoothed measurements.

of the FX1162 flash lamp for its contamination due to NO. The corresponding difference between the originally measured photoelectron currents and this scaled NO-current is shown with the dark blue diamonds in the same figure. Comparing this corrected photoelectron current profile with the profiles due to the different flash lamps reveals that the gradient of all three profiles seen above $95 \mathrm{~km}$ is in fact very close which further supports the trustworthiness of the performed correction.

The next thing to notice is that the currents due to the flashlamp with the largest maximum photon energy are largest whereas the currents due to the flashlamp with lowest maximum photon energy is lowest. At first sight this might be seen as a trivial result since also the total number of photons available for photoionization varies accordingly (see Fig. 2 and corresponding discussion). However, we will see below that there is more information contained in the relative variation of the photoelectron currents owing to the three different flash lamps.

In order to compare the photoelectron current profiles more quantitatively, we have next determined ratios between the different profiles for all values which exceeded the $2 \sigma$ noise level in both profiles. These ratios are presented in the lower two panels of Fig. 8. To start with the most obvious feature, all of these ratios vary considerably with height, with a general increase, with increasing altitude (even though there are admittedly large variations and also deviations seen from this general behaviour). Note that this is a clear indication that the current ratios are not just trivially caused by different photon fluxes, but that they contain information on the microphysical properties of the particles. This issue will be discussed in detail in Sect. 4 below. 


\section{Discussion}

For a further in depth discussion of the information contained in the photoelectron current ratios presented above, it is instructive to recall the physical basis of the recorded photoelectron currents. Following Rapp and Strelnikova (2009) the ECOMA photoelectron current for monodisperse particles with radius $r_{\mathrm{p}}$ and number density $N_{\mathrm{p}}$ can be written as

$I=N_{\mathrm{p}} \cdot\left(\int_{2,5 \mathrm{~cm}}^{v_{\mathrm{e}} \cdot \Delta t} \int_{\lambda_{\min }}^{\omega / W_{\mathrm{p}}} \cdot \frac{d F}{d \lambda} \cdot \sigma\left(r_{\mathrm{p}}, \lambda\right) \cdot P \cdot d l \cdot d \lambda\right) \cdot \frac{e}{\Delta t}$

where $e$ is the electron charge, $v_{\mathrm{e}}$ is the velocity of a photoelectron, $\Delta t=10 \mu \mathrm{s}$ is the sampling interval during which photoelectrons are recorded, $h$ is Planck's constant, $c$ is the speed of light, and $W_{\mathrm{p}}$ is the threshold energy for photoionization/photodetachment of a particle, i.e., the work function or electron affinity of the corresponding material. $d F / d \lambda$ is the number of photons per wavelength interval emitted in one flash, and $l$ is the distance from the particle detector. $P=S /\left(4 \pi l^{2}\right)$ is the probability that the photoelectron is emitted towards the detector electrode with area $S$ and $d l$ and $d \lambda$ are the length and wavelength elements over which the integrations above are carried out. Note that the integration over the wavelength $\lambda$ starts at the flash lamp dependent cut-off wavelength $\lambda_{\min }$ which is defined by the transmission properties of the three different window materials and which is clearly seen in Fig. 2 as the minimum wavelength at which the measured intensity departs from zero. For lamp type FX1160, where the cut-off wavelength could not be properly observed, we extrapolated linearly from the measured value at the lowest detectable wavelength to zero at the nominal cut-off wavelength of $225 \mathrm{~nm}$. We note that the final result of the calculations presented below did not vary considerably if a slightly different extrapolation to zero was chosen. Finally, $\sigma\left(r_{\mathrm{p}}, \lambda\right)$ is the photoionization/photodetachment crosssection of particles with radius $r_{\mathrm{p}}$ at photon wavelength $\lambda$.

This equation shows that there are two factors which could lead to an altitude variation of the observed current ratios, namely a corresponding altitude variation of the work function $W_{\mathrm{p}}$ and the photoemission cross-section $\sigma$. Even though not obvious at first sight, we note that both quantities are actually not independent, but are both a function of the particle size. While this appears obvious for the case of the photoemission cross-section (see e.g., Rapp, 2009, and the discussion therein), this size dependence might not be that obvious for the case of the work function.

Assuming that MSP may be treated as small conducting spheres, it has been shown by Wood (1981) and Burtscher et al. (1982) that the corresponding work function depends on the following way on particle radius $r_{\mathrm{p}}$ and the number of positive elementary charges $p$ :
$W_{\mathrm{p}}=W_{\mathrm{p} 0}+\frac{e^{2}(p+1)}{4 \pi \epsilon_{0} r_{\mathrm{p}}}-\frac{5}{8} \frac{e^{2}}{4 \pi \epsilon_{0} r_{\mathrm{p}}}$

where $W_{\mathrm{p} 0}$ is the bulk work function, $e$ is the elementary charge and $\epsilon_{0}$ is the permittivity of space.

At this point, we also have to note that we do not consider the process of photodetachment any further for the explanation of our observations. This is because photodetachment is typically induced by visible photons, because electron attachment energies are small $(<3 \mathrm{eV})$. Since all three flash lamps have pretty much identical spectra at wavelengths beyond $300 \mathrm{~nm}$ (Fig. 2), this implies that there should not be much difference in the photoemission currents produced by the 3 lamps if photodetachment is dominant. However, since there is in fact a large change, we argue that it is photoionization (and not photodetachment) that is mostly taking place.

Figure 9 now shows calculated photoelectron current ratios using Eq. (2) in Eq. (1) for a variety of cases: Top, middle and lower panels show calculated current ratios for the combinations FX1162/FX1160 (top), FX1162/FX1161 (middle) and FX1161/FX1160 (bottom), respectively, where the necessary flash lamp spectra have been taken from our own laboratory measurements (see Fig. 2 and corresponding discussion). Furthermore, the left panels are for calculations where the photoemission cross-section has been approximated by a Rayleigh absorption cross-section for $\mathrm{Fe}_{2} \mathrm{O}_{3}$-particles and assuming that the photoelectron yield is equal to 1 (see Rapp, 2009 , for a discussion of this highly idealized assumption). In contrast, the right-hand side panels show the same type of calculations, but this time arbitrarily assuming that the photoemission cross-section is constant. Finally, different coloured lines in each panel denote different assumed bulk work functions of the material (see middle panels for colour code).

These calculations show several interesting features: To start, Fig. 9 shows that there are only marginal differences between the cases with different assumptions for the photoemission cross-section (i.e., comparing the left panels with the right panels) so that we may tentatively conclude that the actual choice of this cross-section is not critical for the overall observed variation of the photoelectron current ratios. As a robust result, we further see that the current ratios increase with decreasing particle radius. This is caused by the fact that decreasing particle radius results in a larger overall work function (Eq. 2) of the particles with corresponding effect on the wavelength integration limit in Eq. (1). Finally, the results shown in Fig. 9 also show that the choice of the bulk work function shifts the current ratios up and down and also determines at which particle radius the current ratio starts to deviate significantly from a constant behaviour with radius.

How do these calculations fit to our observations? In the observations, we generally see an increase of the current ratios with increasing altitude. According to the calculations shown in Fig. 9, this suggests that we observed smaller 

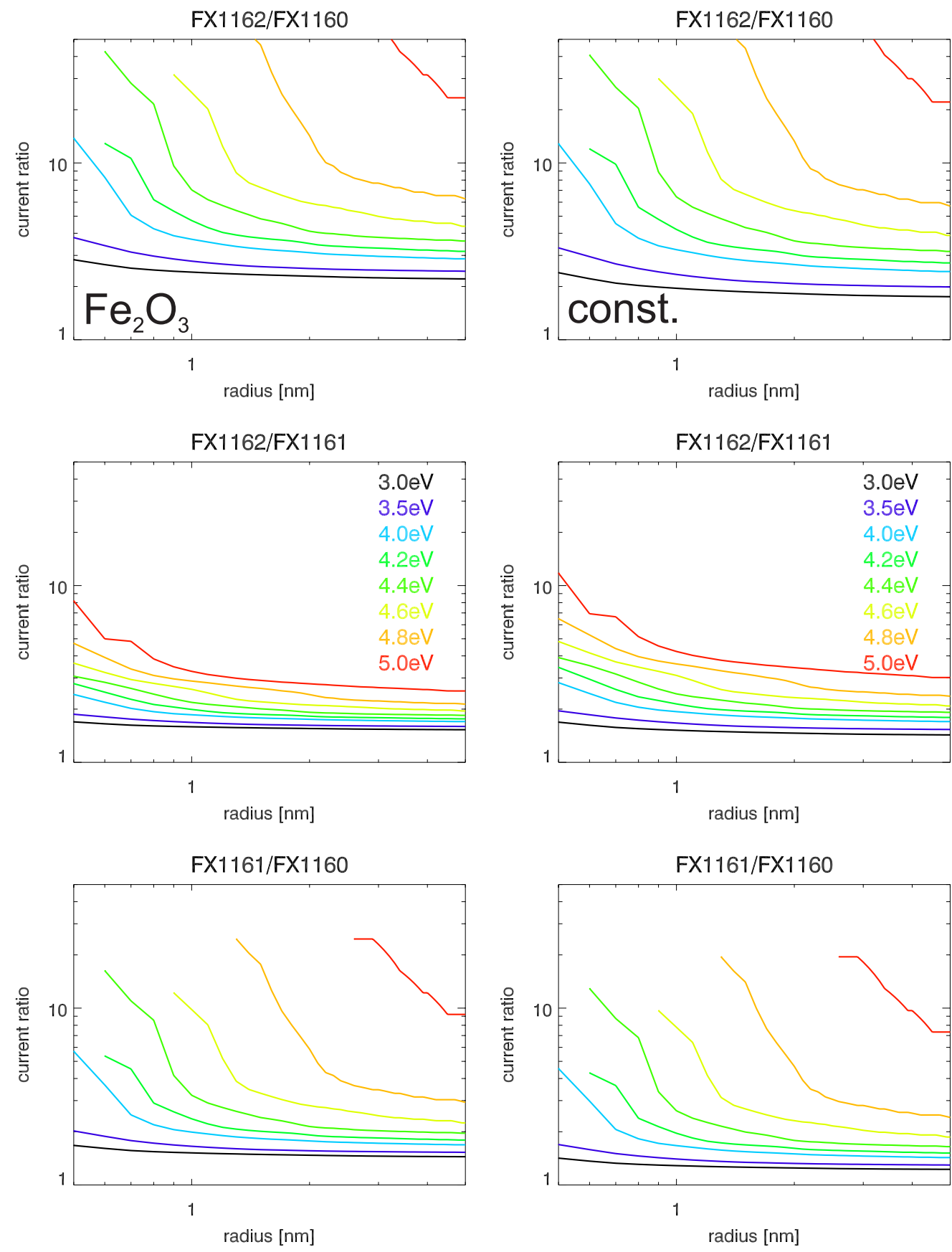

Fig. 9. Calculated photoelectron current ratios for two different assumptions for the photoemission cross-section (i.e., left panels and right panels) and for different combinations of flash lamp types (see title over each panel). In each panel different coloured lines are for different assumed bulk work functions (see insert in middle row panels for colour code).

particles at larger altitudes - which is indeed consistent with all available microphysical models of MSPs (e.g., Hunten et al., 1980; Gabrielli et al., 2004; Megner et al., 2006). Also, comparing absolute values of observed and calculated current ratios, we can further infer that the radii of observed particles must have been in the range from $\sim 0.5-\sim 3 \mathrm{~nm}$ - which is again consistent with the model results quoted above. In addition, we may tentatively convert the observed current ratios into a plausible range of MSP work functions by comparison to Fig. 9. While the lowest work functions (i.e., $<\sim 4 \mathrm{eV}$ ) considered in our calculations appear to be unrealistic (which reconfirms our earlier argument that we are dealing with photoionization rather than photodetachment) since they do not lead to any considerable variation of the 


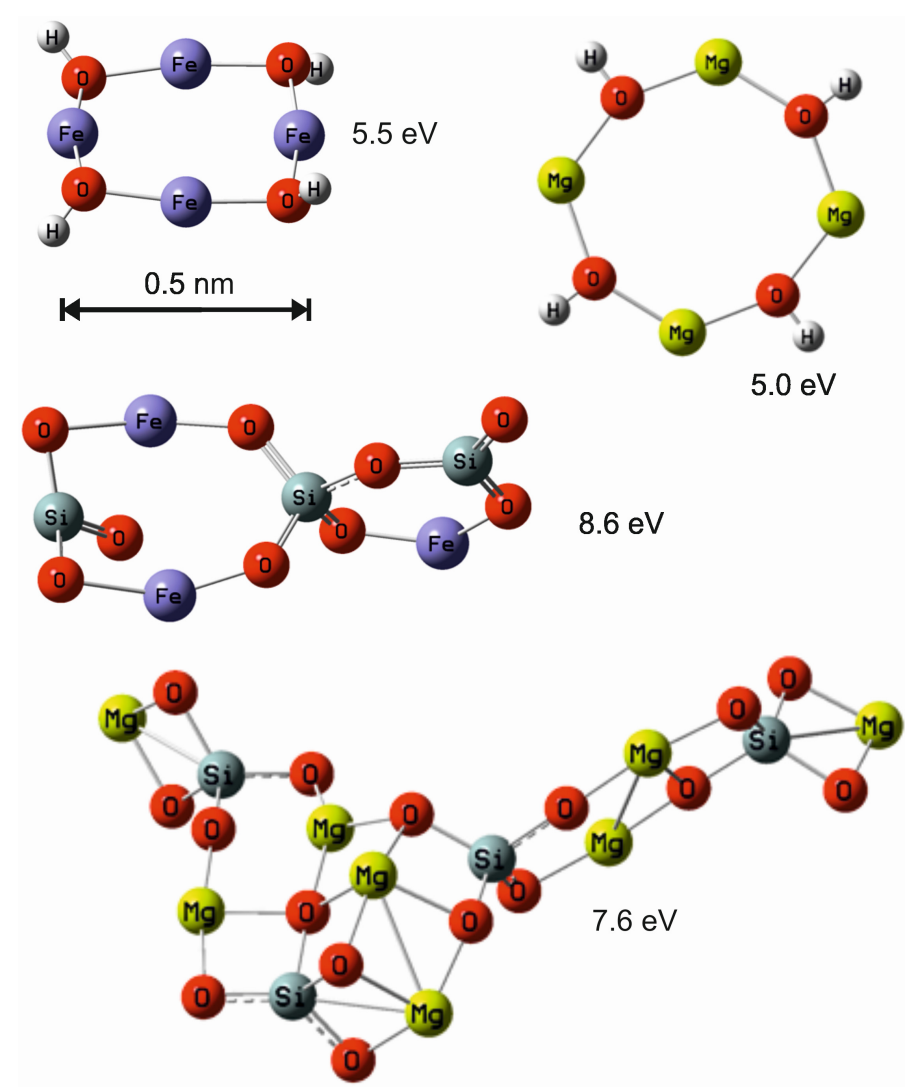

Fig. 10. Optimised geometries of possible embryonic meteoric smoke particles: $(\mathrm{FeOH}) 4,(\mathrm{MgOH}) 4,(\mathrm{FeSiO} 3) 3$ and $(\mathrm{Mg} 2 \mathrm{SiO} 4) 4$. The vertical ionization potentials are shown alongside each cluster.

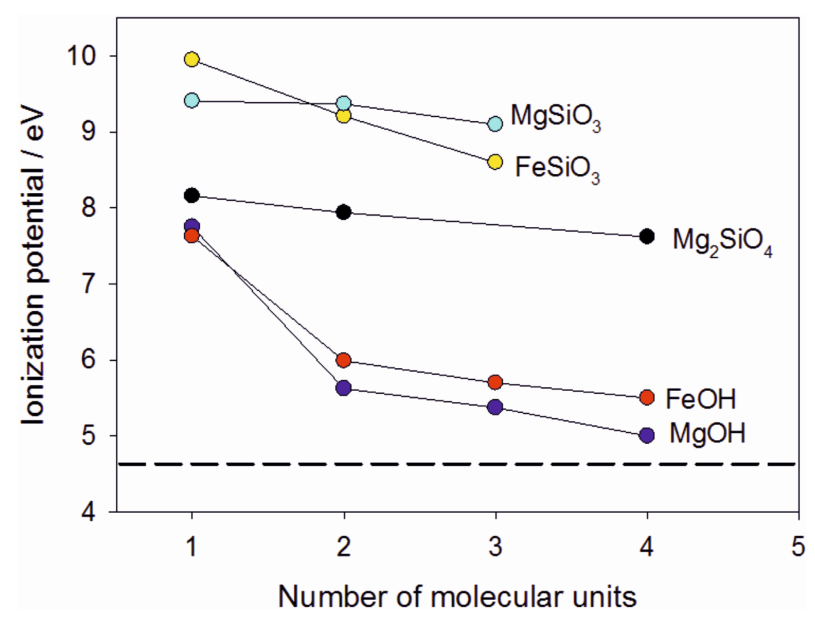

Fig. 11. Ionization potentials for a variety of $\mathrm{Fe}$ and $\mathrm{Mg}$ clusters shown as a function of cluster size, calculated at the B3LYP/6$311+g(2 d, p)$ level of theory. currents with radius (and, hence, with altitude), the largest work functions (i.e., $>\sim 4.6 \mathrm{eV}$ ) appear to lead to unrealistically large current ratios. Hence, the real work function is probably between $4-4.6 \mathrm{eV}$. As we discuss below, a work function in this range is quite hard to account for and constrains the likely composition of the MSP.

We now use electronic structure calculations to explore the possible constituents of MSP. The major elements produced by meteoric ablation are $\mathrm{Fe}, \mathrm{Mg}$ and $\mathrm{Si}$ (Vondrak et al., 2008). Below $90 \mathrm{~km}$, oxidation by $\mathrm{O}_{3}$ and $\mathrm{O}_{2}$ converts $\mathrm{Fe}$ and $\mathrm{Mg}$ into oxides such as $\mathrm{OFeO}_{2}$ (Rollason and Plane, 2000) and $\mathrm{Si}$ is oxidized to $\mathrm{SiO}_{2}$ (Gómez Martín et al., 2009). Laboratory experiments in a photochemical reactor show that a mix of these species will produce $\mathrm{Fe}-\mathrm{Mg}-\mathrm{SiO}_{4}$ nano-particles (Saunders and Plane, 2012). It is, therefore, possible that MSPs have an olivine-type composition. However, in the upper mesosphere there is a large excess of $\mathrm{H}_{2} \mathrm{O}$ over these meteoric constituents (by a factor of $\sim 10^{4}$ ). Reactions involving $\mathrm{H}_{2} \mathrm{O}$ and $\mathrm{H}$ atoms (produced by $\mathrm{H}_{2} \mathrm{O}$ photolysis) are, therefore, likely to convert metal oxides into hydroxides such as $\mathrm{FeOH}$ (Plane and Whalley, 2012; Self and Plane, 2003). Furthermore, theory indicates that $\mathrm{SiO}_{2}$ should hydrolyse to form $\mathrm{OSi}(\mathrm{OH})_{2}$ and $\mathrm{Si}(\mathrm{OH})_{4}$ (Plane, 2012), and that these hydrated forms are unreactive towards $\mathrm{Fe}$ and $\mathrm{Mg}$ 
compounds. It is, therefore, possible that MSP consists of separate populations of metal hydroxide and silicon hydroxide particles. One piece of evidence for this is a recent report that the meteoritic contamination observed by optical extinction in noctilucent ice clouds are $\mathrm{Mg}$-Fe-O compounds, rather than silicates (Hervig et al., 2012).

For the present study, we have carried out theory calculations using the Gaussian 09 suite of programmes (Frisch et al., 2009). The hybrid density functional-Hartree Fock B3LYP method was employed together with the 6$311+\mathrm{G}(2 \mathrm{~d}, \mathrm{p})$ triple zeta basis set. This is a large, flexible basis set which has both polarization and diffuse functions added to the atoms. The geometry of each neutral molecular clusters was first optimised and then the vertical ionization potential (IP) was calculated (i.e., the geometry remains frozen during the process of photoionization). At this level of theory, previous theoretical benchmarking studies indicate an expected uncertainty in the IPs on the order of $\pm 0.3 \mathrm{eV}$ (Foresman and Frisch, 1996).

Figure 10 shows a selection of molecular clusters and Fig. 11 their ionization potentials (IPs) up to a cluster size of 3 or 4 . Note that for the larger clusters the dimensions already exceed $1 \mathrm{~nm}$. Although in all cases there is a decrease in IP with cluster size, the only clusters whose IPs fall below $5.5 \mathrm{eV}$ are $\mathrm{FeOH}$ and $\mathrm{MgOH}$. These IPs should decrease into the range of 4-4.6 eV for larger clusters approaching the dimensions of MSP inferred above (radius $=1-3 \mathrm{~nm}$ ). The IPs of the silicates $\mathrm{FeSiO}_{3}, \mathrm{MgSiO}_{3}$ and $\mathrm{Mg}_{2} \mathrm{SiO}_{4}$ (as an example of an olivine) are well in excess of $7 \mathrm{eV}$ and, thus, unlikely to fall below $4.6 \mathrm{eV}$ even for larger clusters. These results, therefore, indicate that the MSP which exhibit photo-electric emission at wavelengths greater than $300 \mathrm{~nm}$ are probably composed primarily of $\mathrm{Fe}$ and $\mathrm{Mg}$ hydroxides.

\section{Conclusions}

In the current paper, we have presented in situ measurements of MSP from three sounding rocket flights conducted in December 2010. The launch dates were chosen to cover the period of the Geminids which is one of the major meteor showers of the year. One of the scientific objectives to be addressed was whether the additional meteoroid influx during the Geminids resulted in a corresponding increase in relevant MSP properties such as their number density and/or size. Each of the three payloads carried an ECOMA particle detector (PD). This PD is a combination of a classical Faraday cup for the detection of charged heavy aerosol particles and a xenon flashlamp for the active photoionization of MSP and the subsequent detection of photoelectrons. As an additional advance, the PD used in the first and third rocket flight contained three instead of only one flash lamps. Since these three flash lamps were identical except for their different window materials, these two advanced PD types not only provided one profile of photoelectron currents, but also additional information on the spectral content of this photoelectron current which may be used to infer information on the MSP size and work function.

The main results obtained from these three flights are as follows:

- The column density of negatively charged MSPs decreased steadily from flight to flight which is in agreement with a corresponding decrease of the sporadic meteor flux recorded during the same period. This implies that the sporadic meteors are a major source of MSPs, whereas the additional influx due to the shower meteors did not play any significant role.

- Surprisingly, the profiles of photoelectron currents obtained with the flash lamp type used in all three flights are only partly compatible with this observation: while the photoelectron current profiles obtained during the first and third flight of the campaign showed a qualitatively similar behaviour as the MSP charge density data, the profile from the second flight (i.e., at the peak of the Geminids) shows much smaller photoelectron currents. This may tentatively be interpreted as a different MSP composition (and, hence, different photoelectric properties) during this second flight. We note, however, that we are not in a position to conclude that there is a cause and effect relation between the Geminids and this observation at this stage.

- The spectral content of the photoelectron data measured during the first and third flight was compared to a simple model of the photoelectron currents. From this comparison, we tentatively conclude that we observed MSPs in the $0.5-3 \mathrm{~nm}$ size range with generally increasing particle size with decreasing altitude. Notably, this size information can be obtained because different MSP particle sizes are expected to result in different work functions. Importantly, we were able to support this size dependence of the work function by both simple classical arguments as well as quantum chemical calculations.

- Based on the same comparison of spectrally resolved photoelectron currents and the simple model mentioned above the MSP work function can be estimated to lie in the range from $\sim 4-4.6 \mathrm{eV}$.

- Finally, electronic structure calculations indicate that the low work function of the MSP measured by ECOMA indicates that $\mathrm{Fe}$ and $\mathrm{Mg}$ hydroxide clusters, rather than metal silicates, are the major constituents of the smoke particles.

We note that the results presented in this manuscript remain, to some extent, ambiguous until the composition of MSP and the corresponding photoelectrical properties have been directly determined by sampling experiments and corresponding laboratory investigations. However, our results may be 
useful in guiding such future experiments and, in particular, the spectrally resolved photoelectron data obtained within this campaign will be an important dataset for future evaluations of model and laboratory results regarding MSP composition.

Acknowledgements. The ECOMA project was sponsored by the German Space Center under DLR-grants 50OE0301 and 50OE0801. The Norwegian Space Center and the Research Council of Norway supported the Norwegian contribution to the ECOMA programme with funding through grants 197629 and 191754. Thanks to S. Skruszewicz and J. Tiggesbäumker of the Physics Department of Rostock University for supporting the laboratory calibration of the flash lamps. Thanks also to J. Höffner for early discussions on the use of several flashlamps in the ECOMA PD and to I. Strelnikova for support during data analysis. Thanks very much to Hans-Jürgen Heckl for ingeniously designing and building the ECOMA-instrument. Finally, the excellent support of the Andoya Rocket Range and the DLR-Mobile Rocket Base (Moraba) during the entire ECOMA project is gratefully acknowledged.

The service charges for this open access publication have been covered by a Research Centre of the Helmholtz Association.

Topical Editor C. Jacobi thanks A. Barjatya and one anonymous referee for their help in evaluating this paper.

\section{References}

Amyx, K., Sternovsky, Z., Knappmiller, S., Robertson, S., Horányi, M., and Gumbel, J.: In-situ measurement of smoke particles in the wintertime polar mesosphere between 80 and $85 \mathrm{~km}$ altitude, J. Atmos. Sol. Terr. Phys., 70, 61-70, 2008.

Bardeen, C. G., Toon, O. B., Jensen, E. J., Marsh, D. R., and Harvey, V. L.: Numerical simulations of the three dimensional distribution of meteoric dust in the mesosphere and upper stratosphere, J. Geophys. Res., 113, D17202, doi:10.1029/2007JD009515, 2008.

Barjatya, A. and Swenson, C. M.: Observations of triboelectric charging effects on Langmuir-type probes in dusty plasma, J. Geophys. Res., 111, A10302, doi:10.1029/2006JA011806, 2006.

Bekkeng, T. A., Barjatya, A., Hoppe, U.-P., Pedersen, A., Moen, J. I., Friedrich, M., and Rapp, M.: Payload charging events in the mesosphere and their impact on Langmuir type electric probes, Ann. Geophys., in review, 2012.

Borovicka, J.: Properties of meteoroids from different classes of parent bodies, near Earth objects, our celestial neighbours: opportunity and risk, Proceedings IAU Symposium Nr. 236, doi:10.1017/S1743921307003134, 2006.

Burtscher, H., Scherrer, L., Siegmann, H. C., Schmidt-Ott, A., and Federer, B.: Probing Aerosols by photoelectric charging, J. Appl. Phys., 53, 3787-3791, 1982.

Ceplecha, Z., Borovicka, J., Elford, W. G., Revelle, D. O., Hawkes, R. L., Porubcan, V., and Simek, M.: Meteor phenomena and bodies, Space Sci. Rev., 84, 327-471, 1998.
Dunker, T., Hoppe, U.-P., Stober, G., and Rapp, M.: Development of the mesospheric $\mathrm{Na}$ layer at $69 \mathrm{~N}$ during the Geminids meteor shower 2010, Ann. Geophys., in press, 2012.

Ernst, S.: On the absolute calibration of VUV Xe flash lamps used in sounding rocket experiments, Diploma thesis, Technical University Bergakademie Freiberg, 2012.

Fentzke, J. T., Janches, D., Strelnikova, I., and Rapp, M.: Meteoric smoke particles derived using dual beam Arecibo UHF observations of D-region spectra during different seasons, J. Atmos. Sol.Terr. Phys., 71, 1982-1991, doi:10.1016/j.jastp.2009.09.002, 2009.

Foresman, J. B. and Frisch, A.: Exploring chemistry with electronic structure methods, Gaussian Inc., Pittsburgh PA, 1996.

Frisch, M. J., Trucks, G. W., Schlegel, H. B., Scuseria, G. E., Robb, M. A., Cheeseman, J. R., Scalmani, G., Barone, V., Mennucci, B., Petersson, G. A., Nakatsuji, H., Caricato, M., Li, X., Hratchian, H. P., Izmaylov, A. F., Bloino, J., Zheng, G., Sonnenberg, J. L., Hada, M., Ehara, M., Toyota, K., Fukuda, R., Hasegawa, J., Ishida, M., Nakajima, T., Honda, Y., Kitao, O., Nakai, H., Vreven, T. J. A., Montgomery, J., Peralta, J. E., Ogliaro, F., Bearpark, M., Heyd, J. J., Brothers, E., Kudin, K. N., Staroverov, V. N., Kobayashi, R., Normand, J., Raghavachari, K., Rendell, A., Burant, J. C., Iyengar, S. S., Tomasi, J., Cossi, M., Rega, N., Millam, J. M., Klene, M., Knox, J. E., Cross, J. B., Bakken, V., Adamo, C., Jaramillo, J., Gomperts, R., Stratmann, R. E., Yazyev, O., Austin, A. J., Cammi, R., Pomelli, C., Ochterski, J. W., Martin, R. L., Morokuma, K., Zakrzewski, V. G., Voth, G. A., Salvador, P., Dannenberg, J. J., Dapprich, S., Daniels, A. D., Farkas, O., Foresman, J. B., Ortiz, J. V., Cioslowski, J., and Fox, D. J.: Gaussian 09, Revision A.1, Gaussian Inc., Wallingford CT, 2009.

Gabrielli, P., Barbante, C., Plane, J. M. C., Varga, A., Hong, S., Cozzi, G., Gasparia, V., Planchon, F. A. M., Cairns, W., Ferrari, C., Crutzen, P., Ceson, P., and Boutron, C. F.: Meteoric smoke fallout over the holocene epoch revealed by iridium and platinum in Greenland ice, Nature, 432, 1011-1014, 2004.

Gelinas, L. J., Lynch, K. A., Kelley, M. C., Collins, S., Baker, S., Zhou, Q., and Friedman, J. S.: First observation of meteoritic charged dust in the tropical mesosphere, Geophys. Res. Lett., 25, 4047-4050, 1998.

Gómez Martín, J. C., Blitz, M. A., and Plane, J. M. C.: Kinetic studies of atmospherically relevant silicon chemistry. Part II: Silicon monoxide reactions, Phys. Chem. Chem. Phys., 11, 1094510954, 2009.

Havnes, O., Trøim, J., Blix, T., Mortensen, W., Næsheim, L. I., Thrane, E., and Tønnesen, T.: First detection of charged dust particles in the Earth's mesosphere, J. Geophys. Res., 101, 1083910847, 1996.

Hedin, J., Gumbel, J., and Rapp, M.: On the efficiency of rocketborne particle detection in the mesosphere, Atmos. Chem. Phys., 7, 3701-3711, doi:10.5194/acp-7-3701-2007, 2007.

Hedin, J., Rapp, M., Khaplanov, M., Stegman, J., and Witt, G.: Observations of NO in the upper mesosphere and lower thermosphere during ECOMA 2010, Ann. Geophys., 30, 1611-1621, doi:10.5194/angeo-30-1611-2012, 2012.

Hervig, M. E., Gordley, L. L., Deaver, L. E., Siskind, D. E., Stevens, M. H., III, J. M. R., Bailey, S. M., Megner, L., and Bardeen, C. G.: First satellite observations of meteoric smoke in the upper atmosphere, Geophys. Res. Lett., 113, L18805, 
doi:10.1029/2009GL039737, 2009.

Hervig, M. E., Deaver, L. E., Bardeen III, C. G., J. M. R., Bailey, S. M., and Gordley, L. L.: The content and composition of meteoric smoke in mesospheric ice particles from SOFIE observations, J. Atmos. Sol. Terr. Phys., 84-85, 1-6, 2012.

Horányi, M., Gumbel, J., Witt, G., and Robertson, S.: Simulation of rocket-borne particle measurements in the mesosphere, Geophys. Res. Lett., 26, 1537-1540, 1999.

Horányi, M., Robertson, S., Smiley, B., Gumbel, J., Witt, G., and Walch, B.: Rocket-borne mesospheric measurement of heavy ( $\mathrm{m}$ $\gg 10 \mathrm{amu}$ ) charge carriers, Geophys. Res. Lett., 27, 3825-3828, 2000.

Hunten, D. M., Turco, R. P., and Toon, O. B.: Smoke and Dust Particles of Meteoric Origin in the Mesosphere and Stratosphere, J. Atmos. Sci., 37, 1342-1357, 1980.

Lynch, K. A., Gelinas, L. J., Kelley, M. C., Collins, R. L., Widholm, M., Rau, D., MacDonald, E., Liu, Y., Ulwick, J., and Mace, P.: Multiple sounding rocket observations of charged dust in the polar winter mesosphere, J. Geophys. Res., 110, A03302, doi:10.1029/2004JA010502, 2005.

Megner, L., Rapp, M., and Gumbel, J.: Distribution of meteoric smoke - sensitivity to microphysical properties and atmospheric conditions, Atmos. Chem. Phys., 6, 4415-4426, doi:10.5194/acp-6-4415-2006, 2006.

Megner, L., Siskind, D. E., Rapp, M., and Gumbel, J.: Global and temporal distribution of meteoric smoke: A twodimensional simulation study, J. Geophys. Res., 113, D03202, doi:10.1029/2007JD009054, 2008.

Plane, J. M. C.: Atmospheric chemistry of meteoric metals, Chem. Rev., 103, 4963-4984, 2003.

Plane, J. M. C.: On the nucleation of dust in stellar outflows, Phil. Trans. Roy. Soc. A, in press, 2012.

Plane, J. M. C. and Whalley, C. L.: A new model for magnesium chemistry in the upper atmosphere, J. Phys. Chem. A, 116, 62406252, 2012.

Rapp, M.: Charging of mesospheric aerosol particles: the role of photodetachment and photoionization from meteoric smoke and ice particles, Ann. Geophys., 27, 2417-2422, doi:10.5194/angeo-27-2417-2009, 2009.

Rapp, M. and Lübken, F.-J.: Modelling of particle charging in the polar summer mesosphere: Part 1 - general results, J. Atmos. Sol. Terr. Phys., 63, 759-770, 2001.

Rapp, M. and Strelnikova, I.: Measurements of meteor smoke particles during the ECOMA-2006 campaign: 1. particle detection by active photoionization, J. Atmos. Sol. Terr. Phys., 71, 477-485, 2009.

Rapp, M. and Thomas, G. E.: Modeling the microphysics of mesospheric ice particles: Assessment of current capabilities and basic sensitivities, J. Atmos. Sol. Terr. Phys., 68, 715-744, 2006.

Rapp, M., Hedin, J., Strelnikova, I., Friedrich, M., Gumbel, J., and Lübken, F.-J.: Observations of positively charged nanoparticles in the nighttime polar mesosphere, Geophys. Res. Lett., 32, L23821, doi:10.1029/2005GL024676, 2005.

Rapp, M., Strelnikova, I., and Gumbel, J.: Meteoric smoke particles: evidence from rocket and radar techniques, Adv. Space Res., 40, 809-817, doi:10.1016/j.asr.2006.11.021, 2007.

Rapp, M., Strelnikova, I., Strelnikov, B., Hoffmann, P., Friedrich, M., Gumbel, J., Megner, L., Hoppe, U.-P., Robertson, S., Knappmiller, S., Wolff, M., and Marsh, D. R.: Rocket-borne in-situ measurements of meteor smoke: charging properties and implications for seasonal variation, J. Geophys. Res., 115, D00I16, doi:10.1029/2009JD012725, 2010.

Rapp, M., Strelnikova, I., Strelnikov, B., Friedrich, M., Gumbel, J., Hoppe, U.-P., Blix, T., Havnes, O., Bracikowski, P., Lynch, K., and Knappmiller, S.: Microphysical properties of mesospheric aerosols: An overview of in situ-results from the ECOMA-project, in: Aeronomy of the Earth's Atmosphere and Ionosphere, Springer Science+Business Media B. V., edited by: Abdu, M. A., Pancheva, D., and Bhattacharyya, A., IAGA Special Sopron Book Series, pp. 67-74, 10.1007/978-94-007-03261_4, 2011.

Rollason, R. J. and Plane, J. M. C.: The reactions of $\mathrm{FeO}$ with $\mathrm{O}_{3}$, $\mathrm{H}_{2}, \mathrm{H}_{2} \mathrm{O}, \mathrm{O}_{2}$ and $\mathrm{CO}_{2}$, Phys. Chem. Chem. Phys., 2, 1094510954, 2000.

Saunders, R. W. and Plane, J. M. C.: A laboratory study of meteor smoke analogues: Composition, optical properties and growth kinetics, J. Atmos. Sol. Terr. Phys., 68, 2182-2202, 2006.

Saunders, R. W. and Plane, J. M. C.: A photo-chemical method for the production of olivine nanoparticles as cosmic dust analogues, Icarus, 212, 373-382, 2012.

Schulte, P. and Arnold, F.: Detection of upper atmospheric negatively charged microclusters by a rocket borne mass spectrometer, Geophys. Res. Lett., 19, 2297-2300, 1992.

Self, D. E. and Plane, J. M. C.: A kinetic study of the reactions of iron oxides and hydroxides relevant to the chemistry of iron in the upper atmosphere, Phys. Chem. Chem. Phys., 5, 1407-1418, 2003.

Stober, G., Schult, C., Baumann, C., Latteck, R., and Rapp, M.: The Geminid Meteor Shower during the ECOMA Sounding Rocket Campaign: specular and head echo radar observations, Ann. Geophys., in review, 2012.

Strelnikova, I., Rapp, M., Raizada, S., and Sulzer, M.: Meteor smoke particle properties derived from Arecibo incoherent scatter radar observations, Geophys. Res. Lett., 34, L15815, doi:10.1029/2007GL030635, 2007.

Strelnikova, I., Rapp, M., Strelnikov, B., Baumgarten, G., Brattli, A., Svenes, K., Hoppe, U.-P., Friedrich, M., Gumbel, J., and Williams, B.: Measurements of meteor smoke particles during the ECOMA-2006 campaign: 2. results, J. Atmos. Sol. Terr. Phys., 71, 486-496, 2009.

Summers, M. E., Conway, R. R., Englert, C. R., Siskind, D. E., Stevens, M. H., Russel, J. M., Gordley, L. L., and McHugh, M. J.: Discovery of a water vapor layer in the arctic summer mesosphere: implications for polar mesospheric clouds, Geophys. Res. Lett., 28, 3601-3604, 2001.

Voigt, C., Schlager, H., Luo, B. P., Dörnbrack, A., Roiger, A., Stock, P., Curtius, J., Vössing, H., Borrmann, S., Davies, S., Konopka, P., Schiller, C., Shur, G., and Peter, T.: Nitric Acid Trihydrate (NAT) formation at low NAT supersaturation in Polar Stratospheric Clouds (PSCs), Atmos. Chem. Phys., 5, 13711380, doi:10.5194/acp-5-1371-2005, 2005.

Vondrak, T., Plane, J. M. C., Broadley, S., and Janches, D.: A chemical model of meteoric ablation, Atmos. Chem. Phys., 8, 70157031, doi:10.5194/acp-8-7015-2008, 2008.

Wood, D. M.: Classical size dependence of the work function of small metallic spheres, Phys. Rev. Lett., 46, 749, 1981. 